\title{
X-ING DISCIPLINES FROM ARCHITECTURE. THE CASE OF AALTO ARTS
}

\author{
A. Ahlava; F. Nieto \\ Group X, Department of Architecture \\ School of Arts, Design and Architecture \\ Aalto University \\ fernando.nieto@aalto.fi
}

\begin{abstract}
In the last years, the new notions of architecture and the new roles of architects have caused strong changes regarding architectural education. These changes are demanding a user-driven strategy more focused on human experiences and a holistic view of the discipline. This strategy entails the restructuration of architectural studies, requiring interdisciplinary action with other agents such as engineers, economists or designers.

The School of Arts, Design and Architecture at Aalto University (Aalto ARTS) has been aiming since 2010 to blur the boundaries between studies and professional practice, encouraging the search of a new type of professional who is belated student and newcomer worker at the same time. Multidisciplinary co-working spaces at university premises act as incubators, sheltering experienced students and young professionals. The article aims to explain this situation, focusing on the Department of Architecture and the role of Group X, an academic group, which stimulates collaboration between disciplines.
\end{abstract}

Key words: architectural education; multidisciplinary; collaborative; co-working

\section{RESUMEN}

En los últimos años, las nuevas nociones de arquitectura y el papel de los arquitectos han supuesto fuertes cambios respecto a la educación en arquitectura. Estos cambios demandan una estrategia orientada hacia el usuario más centrada en las experiencias humanas y en una visión integral de la disciplina. Esta estrategia implica la reestructuración de los estudios de arquitectura, lo que requiere una acción interdisciplinaria con otros agentes tales como ingenieros, economistas o diseñadores.

La Escuela de Arte, Diseño y Arquitectura de la Universidad Aalto (Aalto ARTS) impulsa desde 2010 desdibujar los límites entre los estudios y la práctica profesional, fomentando la búsqueda de un nuevo tipo de profesional que es estudiante tardío y trabajador novel al mismo tiempo. Espacios multidisciplinares de trabajo colaborativo en la universidad actúan como, albergando estudiantes experimentados y jóvenes profesionales. El artículo pretende explicar esta situación, centrándose en el Departamento de Arquitectura y el papel del Grupo $\mathrm{X}$, un grupo académico que potencia la colaboración entre disciplinas.

Palabras clave: educación en arquitectura; multidisciplinario; colaborativo; trabajo en común 


\section{INTRODUCTION}

In the last years, architectural education has undergone major changes, stemming from the new notions of architecture, the increasingly changing roles of architects and the new modes of action within the discipline itself. These changes require strategic development based on a user-driven strategy more focused on human experiences and a holistic view of the discipline. This strategy implies aspects such as a more comprehensive view of the living environment, a responsive management of the relationships between different scales, and working methods based on intensive collaboration. In this context, education in ARTS and specifically in Architecture are expected to play a special role in creating human-friendly environments, beyond worn-out debates concerning the dichotomies of theory or practice, research or teaching, and artistic or technical studies. Thus, the strategy in ARTS entails restructuring of graduate and postgraduate architectural studies, requiring interdisciplinary action involving other agents such as engineers, economists or designers.

Architectural profiling increasingly demands collaboration between different disciplines. However, multidisciplinary skills might be considered as threatening architect's accreditation. In Finland, young graduated (Master's level) architects must not comply with any accreditation to start working as designing architects. Most of them have worked before finishing their studies, having gathered at the time of graduation sufficient experience or professional expertise to launch a career.

Financial principles for architectural studies in Finland base on a paradox regarding the length of studies. On one hand, the Ministry of Education supports shorter studies in order to reduce financing per student and speeding the transfer of students from universities to professional work. On the other hand, the longer the studies become, the better architects are graduating. Study times are usually longer when students are already working before finishing their studies. Thereby, they receive professional experience during studies, which is very useful for the stage after graduation.

Blurring boundaries between studies and professional practice makes the step from university to the actual markets broaden and soften easily. Ultimately, in ARTS, this aims at educating a new type of professional who is belated student and newcomer worker at the same time.

\section{DIALOGIC-BASED EDUCATION. AALTO ARTS}

Starting on the first of January 2012, the Aalto University School of Art and Design and the Department of Architecture of the School of Engineering merged to form Aalto ARTS. The first part of the school's name emphases humanorientedness, which is the cornerstone of all teaching and research. There is a Nordic ideological background for this: the advanced welfare state, which takes care also of the disadvantaged. The second part of the name centres on practicality and good design, which produce better and more responsible living environments.

The world's best universities in the fields of architecture, design and art are often characterized by a strong tradition in the education of art, which integrates competences relating to design, commerce and technology. The core of research 
and teaching at Aalto ARTS consists of art as well, which has an important position in the research, thinking, methods, expression and culture of the School's various fields of study. In the community at Aalto University, art compares to scientific basic research; research and art outline academic results from their own starting points. Aalto University is aiming to be an international pioneer in scientific-artistic integration.

Art education is generally understood as a dialogic education (Muntañola, 2004), where dialogue appoints attention and sensitiveness in the relation with other people (Sennet, 2012). The success and uniqueness of Aalto ARTS base on a close integration of research, teaching and artistic activity as well as cooperation with industry, business life at large and society. According to its mission and strategy, Aalto University works towards a better world through top-quality research and teaching and educates responsible experts as society's visionaries. Aalto ARTS realizes the University's mission by promoting responsible and usercentered design as well as creative attitudes and implementation in different scales and media. Multidisciplinary research and independent artistic activities create a foundation for the University's operation. Education is supported by independent, cross-disciplinary, human-centered and practice-based research and artistic work.

Establishing the School was a strategic choice for Aalto University. It was associated with ambitious goals such as renewing the content of the degree programs, lifting research to an international level, creating an inspiring and energizing learning experience, and influencing national and international reforms in the fields concerned.

There is something un-Finnish in the boldness and high aspirations of the targets of the success of the university. Modesty and failures have more mythological resonance in the stereotypical Finnish mind-set. The systematic approach is still typical.

The new school is a strategic choice for Aalto University and a means to gain international profile. It brings together the areas of designing and implementing human-oriented environments as well as the areas of research and teaching based on humanistic and cultural traditions. It combines academic thinking with relevant practical research topics, and profiles architecture and art education in relation to other universities in the sector. It aims towards:

- A change in innovation thinking.

- Along with a technological approach, human- and user-centered attitudes are emphasized.

- A need for new social and cultural innovation.

- The global requirements of our surrounding society.

- Sustainable development and responsibility.

- A need to comprehensively understand and be able to manage environments in different scales.

The achievement of the goals requires:

- Strategic positioning of research and the launch of horizontal themes.

- Enhancing the prerequisites and support for research.

- Reforming and profiling the study programs. 
- Boosting connections with other schools at Aalto University.

- Reforming joint teaching activities.

- Defining and clarifying the artistic profile.

- Verifying the results of activities.

- A strong commitment from the community and active communication.

Despite our limited resources the high goals can at least theoretically be achieved because of the excellent student material. The reports on Finnish school system and the abilities of school children (PISA rankings) have for a long period been at the top of the world. At least for architecture, the entrance exam system has also been able to select the most able and talented students to the field, emphasizing creativity. The profession of an architect is also much respected in Finland and this has kept the architecture schools also very attractive study places.

\subsection{Artistic activities}

Art plays an important role in the uniqueness and identity of Aalto University School of Arts, Design and Architecture. Art is considered a foundation for enthusiastic and energizing discussion and action, with strong connections with ethics, aesthetics and ecology. Art is also a key to the construction of a learning experience and attitude.

The basis for art and research at Aalto University School of Arts, Design and Architecture are critical thinking, creative problem solving, open-mindedness and courage. The School's set of values also emphasize responsibility and the desire to make the world and society human-oriented, open and tolerant. In our conception, creativity aims at a better everyday life. Emphasizing the quality of the everyday instead of luxurious design is at the core of not only Finnish, but Nordic architectural and design tradition. Creating good results from limited resources is our skill.

The profile of the Aalto University School of Arts, Design and Architecture embodies the characterization of art along with research and teaching. In the community at Aalto University, art is compared with scientific basic research. Aalto University is an international pioneer in scientific-artistic integration.

What's the role of art in Finland in general? -Internationally most successful Finnish artists are nowadays composers and conductors of classical music. Finnish photography and media art is respected, but architecture is generally considered not as progressive as in the 1950's for example. Simultaneously architects have lost some of their good salaries and societal influence. By associating themselves with both engineers and artists, architects are often difficult to be understood in the society.

\subsubsection{The goals of artistic activities}

2015

- The strategy and focus areas of art profile the School and guide the allocation of resources and tenure track appointments.

- Achievements in the sectors of art, architecture, media and design are the criteria used in tenure track assessments. 
- Indicators that reflect the quality and influence of art have been specified so they can be compared with the best schools in the various areas of expertise.

- The contents of general art education have been defined by taking into account the expansion of the School's areas of expertise.

- The School has artist-in-residence activities that cover its areas of expertise.

2020

- The close integration between art, research and teaching creates a strong identity for the School and makes it a sought-after international partner.

- The School has popular artist-in-residence activities that cover all the various fields.

- The up-to-date infrastructure in studios and workshops has been constructed for research and teaching.

\subsection{Research activities}

Aalto University School of Arts, Design and Architecture create a foundation for research and education in user and human-centered design where usability relates to environments and channels of different scales. The user-centered approach is strongly linked to interaction as well as active participation by individuals and communities. This social approach is clearly culturally embedded in the whole nation and now also supported by the present law of land-use and construction, which emphasizes participatory processes.

A common frame of reference to the areas of research at ARTS is formed by sustainable development and its financial, social, cultural and ecological dimension.

The uniqueness of research is enhanced by the connection between theoretical expertise and practical relevance, on the one hand, and artistic expression on the other hand.

\subsubsection{The goals of research activities}

2015

- The strategic focus areas in research guide the allocation of resources, tenure track appointments, and the formation of research groups.

- Research funding has increased and become more diverse.

- Close integration between research, teaching and art.

- The critical mass and post doc positions of researchers have increased.

- The School uses indicators of research quality and influence that describe its uniqueness.

2020

- Leading European research groups in the focus areas.

- The School has a close-knitted, interactive and multidisciplinary research community.

- A method of operation that supports uniqueness and identity that combines academic thinking, artistic activities and practical relevance of research.

- The School is an interesting research partner at the international level.

Again, international competitiveness has become the goal of the university. Finns have had a special interest in their reputation attained through sports 
achievements in international competitions such as Olympic Games. Maybe the emphasis of Aalto University in strategic-scale international competition - instead of betting on the work of individuals - is a characteristic of a small nation in order to get attention.

\subsection{Teaching activities}

The recent Teaching Evaluation Exercise highlighted the fragmentation of teaching at our school. The abundance of degree programs turns them into independent entities with little communication between them. A key objective based on the results of the teaching evaluation is to reform degree programs by whittling down the number of programs and clarifying their profiles.

The starting points for reforming the degree programs are:

- The strategy of Aalto University.

- The evaluation of teaching.

- Changes in the operating environment.

- Benchmarks.

- Regulations and restrictions.

- The development of teaching.

- Design thinking.

The results of the reform of the degree programs will be:

- The programs will have clear profiles and be up to date.

- Education reform.

- The status of an international pioneer in teaching and learning.

- Increased attractiveness of the School of Arts, Design and Architecture.

- A new degree structure.

- Efficient and user-centered student services.

\subsubsection{Goals in teaching activities}

2015

- The BA and MA programs have been reformed and the programs have a clear profile.

- General teaching has been reformed to support the School's identity and uniqueness.

- Flexible study opportunities inside the School.

- Incentives for international mobility of students.

2020

- Up-to-date study infrastructure.

- Development of study contents together with key partners.

- Significant reductions in study times at Bachelor level.

The development of Aalto University is a national project, financed by the state and many large technology companies, who are also represented in the private foundation governing the university. The companies are expecting a new generation of workers, which is more cross-disciplinary and has a better understanding of economic and social tendencies of the world. 


\subsection{Societal impact}

Based on the results of the Research Assessment Exercise (RAE 2009), as potential areas of strong social impact, the research assessment exercise emphasized art and architecture. The assessment highlighted digitalization and services, the service economy, sustainable use of energy and natural resources as well as a human-oriented environment as ascending, multidisciplinary themes. All the various fields of the School of Arts, Design and Architecture have a central role in the development of a human-centered living environment, a creative society and a vital culture.

At the same time, everyone is touched by the demand for sustainable development and the growing need for comprehensive understanding and responsible management of environments in different scales as well as for creative cultural development. These factors are also centrally displayed in the premises of change in innovation thinking.

\subsubsection{The goals for societal impact}

2015

- Advisory boards consisting of people outside the School and its departments and alumni activities strengthen relations with society at large.

- Thematic partnership relations, based on strategic choices, in applied research

- Extensive national and international media visibility.

- Development of companies established in the School.

2020

- The University has its own "Aalto Agora", which presents results of the activities in an extensive and diversified manner.

- Deep and close relations with international partners.

- The School's projects in social responsibility strengthen the Aalto brand.

From the basis of its unique method of operation, Aalto ARTS brings together the areas of designing and implementing human-oriented environments. It responds to the change in innovation thinking where human- and user-centered attitudes are emphasized along with a technological approach. Finland has recently been very successful in technology industry (with high-tech companies like Nokia and Kone) and technology is generally considered important for the national competitiveness. The cold climate also emphasizes the need for developed technology for example in building insulation and durability. However the humancentered approach strengthens the status of architecture, art, media and design in the Finnish culture and economy and society at large and solidifies research and teaching based on a humanistic and cultural tradition inside the university. It also profiles architecture and education of art in relation to other universities in the sector on the basis of cooperation and interaction between the fields and creates a foundation for the development of social and cultural innovation as well as for production-related, financial and structural solutions required by sustainable development.

The former mythological cultural background of design education has been turned into more calculable machinery for international success.

3 LEARNING VS. TEACHING. THE DEPARTMENT OF ARCHITECTURE 
The Department of Architecture at Aalto University is the oldest and largest of the three schools of architecture in Finland. Since 1872, the architectural education in Finland has followed the European tradition of architectural education as part of the technical sciences. For architecture, this has meant especially the Bauhaus tradition and its ideas that architecture is simultaneously a form of art combining all visual arts with an emphasis in perception and that an architect is capable of operating in any scale. Simply put, the Finnish architectural tradition has its roots in German engineering and that can still be seen in the present typical Finnish architecture. However, the Finnish architectural scene has traditionally received international influence also elsewhere and for example the influence of Jugendstil, Art Nouveau and Henry Hobson Richardson to the development of Finnish garden city ideas and even natural mysticism must be mentioned. At the moment the vague cultural background of architectural education have turned into conscious political plans, whose aim is to promote Finnish competitiveness.

Our Department of Architecture has an international reputation stemming from the Finnish regional architectural culture. The school accepted only $8 \%$ of applicants in 2012 and according to this fact and the success of graduates, it is the best architecture school in Finland. Finland also has two other schools of architecture in Tampere and Oulu. In Aalto University, architecture is regarded as an art requiring learning of professional practice, personal artistic development and technical knowledge of building. Our teaching faculty consists of leading practitioners who have an active career in design projects and competitions. The pragmatic tradition of the school has maintained an esteemed line and guaranteed a high professional skill of the graduates. Talking in terms of national cultural stereotypes can be dangerous, but there is something typically Finnish in the pragmatic and hands-on attitude of our architectural attitude.

One aspect of this pragmatism is that most of the students work in architectural offices parallel to their studies. This causes long study times (nowadays 9-10 years generally for an architect's accreditation), but guarantees the practical abilities of a graduate. One could say that half of the education comes from architects' offices through this master - apprentice relationship situation in offices.

The Department of Architecture has degree programs in architecture and landscape architecture. The school is organized in main theme subjects in architecture, consisting of History of Architecture, Building Design and Urban Planning and Design. Landscape Architecture consists of Landscape Planning and Management and Landscape Design and Construction. Building design, urban design and planning and landscape architecture are closely integrated together in our education. Basically any Finnish architect can succeed in all of these fields with the same education. Our landscape architects understand also building design. The integration of the building, urban and landscape spheres means that buildings cannot be conceived separately from their urban and natural context.

About 550 Finnish degree students in architecture, 120 Finnish degree students in landscape architecture and c.70 Finnish postgraduate research students study at the Department. The annual amount of international exchange or guest students is about 70 . These numbers mean that our school is quite national, 
almost "regional". We are not part of the "global" sphere of architecture schools, where the same international star architects teach anywhere and where the conceptual development of architecture is not always contextual. Instead, we have a strong own cultural and architectural tradition. This does not however mean that a small architectural culture couldn't attain class, international interest and influence.

The Department is situated in Otaniemi, Espoo, on the campus designed by Alvar Aalto. The well-equipped woodwork and metalwork workshops are located in the vicinity of the department. The design of the campus area is based on the idea of a forest settlement by a natural coastline and this relaxed and natural setting also influences the mindsets and activities of students and staff. Alvar Aalto's campus design can be seen belonging to the genre of Finnish midcentury natural simplicity with such other artists and designers as Kaj Franck and Tapio Wirkkala. This Finnish modernism achieved international reputation in foreign magazines and exhibitions, spreading the ideology of simplicity and organicism.

The Department is since first of January 2010, part of the new Aalto University, created through a merger between the Helsinki School of Economics, the University of Art and Design Helsinki and the Helsinki University of Technology. The vision of the university is to enhance multidisciplinary collaborations and knowledge. The ideas behind the birth of Aalto University give also the social, economic, technological and cultural base for the development of our department. It is clear that Aalto University is a national project; an attempt to utilize the multi-disciplinary energies of a small country in a collaborative manner. Aalto's aim is to develop the national competitiveness through cross-disciplinary research and teaching.

\section{COLLABORATIVE LEARNING. AALTO PLATFORMS}

If the progress has overcome the rigidity of Plato's statement "to each his own", so that shoemakers do not have to make just shoes any more (Rancière, 1991), multidisciplinary works seems essential nowadays. Co-working platforms for different disciplines at Aalto University premises, shelter experienced students and young professionals, acting as idea generators and business and professional incubators for collaborative creation of knowledge.

At Aalto platforms, each life moment becomes a learning moment, and selfeducation based on social relations is booted. Thus, the importance of searching for learning colleagues whose interests are the same, or those whose experience is broader, becomes crucial. This peer-matching is one characteristic of good education, which treats to find common interests between students (Illich, 1971).

Aalto platforms are pursuing balance between instruction and education in the sense of blurring their limits (Rancière, 1991).

\subsection{Design Factory}

This is the case of Aalto Design Factory, which welcomes disciplines related to product design, visual culture, digital art, audio visual representation, business, architecture, urban planning and landscape design. 


\subsection{Start-up Sauna}

Startup Sauna has as well boosted the creation of entrepreneurial and interdisciplinary networks between the university and private companies.

\subsection{ADD Lab}

Aalto University Digital Design Laboratory (ADD Lab), a combination of an exhibition space, 3D manufacturing facilities and a research unit, acts as a think tank for digital culture.

\section{QUESTIONING KNOW-HOWS. GROUP X}

Group $X$ is a teaching and research group at the Department of Architecture, aiming to question established education and enhance collaborative learning. Its activities support Beatriz Colomina's definition of radical architectural pedagogies questioning established institutions and blurring boundaries between education, life and work (Colomina, 2012). Group X emphasizes multidisciplinary approaches based on:

\subsection{The culture of sharing - sustainable development}

The culture of sharing is the key philosophy supporting the optimization of the use of premises and infill development. We are interested in the mechanisms and benefits of shared resources, shared technologies and shared spaces. The mechanisms for attaining the targets of sustainability are flexible and mixed use, temporal programming, life cycle thinking and the utilization of the Internet of things in this development. The culture of sharing results in a more social interaction and in a more effectively utilized infrastructure.

\subsection{Happy together - communicative planning}

We want to enhance the co-creation of value through user-centered design and co-design in architectural projects, starting from the very beginnings of the projects and call this approach service architecture. The actual outcomes of this methodology are new types of places for social interaction, networked facilities and services, as well as turning spaces of movement and arrival creatively into new types of urban networks and nodes.

\subsection{Learning as a key to everything - learning organizations and spaces}

Opposing the normative assumption that architecture is about teaching the clients and user how to live, or teaching the architects how people want to live, we support the idea of learning. Architecture should be a place and an activity of collective construction of knowledge for both its creators and users, expanding our understanding of meaningful life and good relationships between the culture and nature. This paradigm shift produces spaces, which are adapted to learn and develop. We work on conceptual and parametric solutions, which support learning cityscapes and learning design and planning processes.

Aalto ARTS has been supporting the eradication of fences between studies and professional practice, encouraging the combination of solid practical skills and academic exploration. The philosophy behind this policy supports the search of a 
new type of designer of artist, who is a student and a newcomer in the business simultaneously. Multidisciplinary co-working spaces at university premises work as the incubators of innovation, sheltering the collaboration of visionary students, companies and young professionals. This article focused on this pedagogic practice, focusing on the Department of Architecture and the role of Group X, an academic group, questioning conventional notions of architecture and enhancing collaboration between disciplines.

\section{BIBLIOGRAPHY}

Ahlava, Antti (2015), "New Tune of Teaching", in Arkkitehti Finnish Architectural Review ark 1/2015 "Young Ideas". Helsinki: SAFA Finnish Association of Architects (pp. 77-79).

Bohm, David (1996), On Dialogue. New York: Routledge.

Colomina, Beatriz et al. (2012), "Radical Pedagogies in Architectural Education", research project at Princeton University (online source, consulted 23.03.15, http://www.architectural-review.com/education/radical-pedagogies-in-architectural -education/8636066.article). London: The Architectural Review.

García Triviño, Francisco A.; Nieto Fernández, Fernando; Psegiannaki, Katerina (Eds., 2014), Hipo 2 "Disobedient Pedagogy", HipoTesis Numbered Issues (online source, consulted 21.03.15, http://www.hipo-tesis.eu/numero_hipo 2.html). Madrid: HipoTesis Platform.

Illich, Ivan (1973), Deschooling Society, Harmondsworth: Penguin.

Muntañola, Josep (2004), "Arquitectura, educación y dialogía social", in Revista española de pedagogía $n^{\circ}$ 228. Madrid: Instituto Europeo de Iniciativas Educativas (pp. 221-228).

Onfray, Michel (2008), La comunidad filosófica / The Philosophical Community. Manifiesto por una universidad popular (trans. Antonia Garcia Castro). Madrid: Gedisa.

Rancière, Jacques (1991), The Ignorant Schoolmaster. Five Lessons in Intellectual Emancipation (trans. Kristin Ross). Stanford, California: Stanford University Press.

Sennet, Richard (2012), Together. The Rituals, Pleasures and Politics of Cooperation. New Haven: Yale University Press New Haven. 